\title{
PRESCRIPTIONS INVOLVING ANALGESIC DRUGS AT A SECONDARY HEALTH FACILITY IN IBADAN, NIGERIA
}

\author{
${ }^{1 *}$ Fehintola F.A. and ${ }^{2}$ Ganiyu A.A. \\ ${ }^{1}$ Department of Pharmacology and Therapeutics, College of Medicine, University of Ibadan, Ibadan, Nigeria \\ ${ }^{2}$ Jericho General Hospital Ibadan, Nigeria
}

Correspondence:

Dr F. A. Fehintola

Email: fentolamine@yahoo.com fehintolaf@comui.edu.ng

\begin{abstract}
Introduction: Pain is a cardinal feature of inflammation and is responsible for majority of hospital visits. The non-opioid analgesics possess antipyretic and anti-inflammatory activity and thus are often employed for such purpose of controlling inflammation as well as antipyretic. The non-opioid analgesics are freely available devoid of causing dependence but their potential harmful effects can sometimes be serious. The need for rational drug use is paramount and requires evaluation of physicians practice to serve as basis for continue medical education.
\end{abstract}

Methods: A retrospective assessment of pattern of prescription at a secondary health facility owned by one of the 36 states of the federation of Nigeria. The age, sex, the drugs prescribed per patient were recorded and prescriptions involving analgesics were further analyzed. Proportions were compared using $\mathrm{X}^{2}$ and statistical significance was set at $\mathrm{p}<0.05$.

Results: Analgesic drugs were commonly prescribed constituting $23.8 \%$ of all the prescriptions recorded in the study. Paracetamol was the most commonly prescribed analgesic drug accounting for $55.7 \%$ of all analgesic drugs prescribed while Dipyrone was the most commonly prescribed parenteral analgesic drug. Dipyrone accounted for $19 \%$ of total Analgesic drug prescriptions but $93 \%$ of analgesics administered by intramuscular route. Dipyrone was also the preferred Analgesic drug in traumatic conditions. No cognizance was taken of the potential of NSAIDs for causing gastrointestinal injury as Diclofenac, Nimesulide and Dipyrone were sometimes used even in patients with peptic ulcer disease.

Conclusions: Pain management with NSAIDs requires some dexterity in particular when certain categories of patients are to be treated. There is need for continue medical education to ensure rational use of these drugs

\section{INTRODUCTION}

Analgesics are broadly divided into two classes, that is, Opioid and non-opioid drugs. Opioids are generally reserved for relieve of severe pain and are usually provided under supervision and strict control because of tendency to dependence and abuse ${ }^{1}$. On the other hand non-opioid analgesics are freely available to patients and they provide remedies for mild to moderate pain. Most of the non-opioid analgesics possess antipyretic and anti-inflammatory activities and are also known as Non Steroidal Antiinflammatory Drugs (NSAIDs) ${ }^{2}$, thus patients who present with sundry conditions may be prescribed a member of this group of drugs. Nonetheless, the use of this group of drugs may be attended by serious untoward effects. The major adverse effects of therapy with these drugs stem from their blockade of the cyclooxygenase pathway, an effect which in addition to control of inflammation, negatively impacts on the renal and gastrointestinal systems ${ }^{2}$.

Ability of non-opioid analgesic to selectively block the inducible cyclo-oxygenase $2(\mathrm{COX}-2)$ provides the rationale for functional classification. The COX-2 selective drugs spare the COX-1 enzymes and are unlikely 
to breach renal and gastrointestinal protective mechanisms ${ }^{2}$. However, chronic use of these COX-2 selective agents has been implicated in some cases of sudden cardiac death. ${ }^{3,4}$ The well known classes of nonopioid analgesics include the Salicylates like Acetylsalicylic acid and the Pyrazolones such as Phenylbutazone. Other classes include: Acetic acid derivatives like Indomethacin and Tolmentin, the Oxicams like Piroxicam, Fenamates like Mefenamic acid, Proprionic acid derivatives, for example, Ibuprofen, Para-aminophenol such as Paracetamol, and the Alkanone derivatives like Nabumetone ${ }^{2}$.

Other members of the Pyrazolone class of nonsteroidal anti-inflammatory drugs include Aminopyrine, Antipyrine, Phenylbutazone, Dipyrone and Oxyphenbutazone. Dipyrone, also known as metamizole, noramidopyrine, novamin sulphone and methampyrone has been available for clinical use since the 1920s. The drug has only weak anti-inflammatory action but analgesic and antipyretic effects are comparable to that of Aspirin ${ }^{2}$. It used to be one of the few non-opioid analgesic drugs available for parenteral use in Nigeria until its ban in the late 2005. The aim of this study was to evaluate the use of Dipyrone and other analgesic drugs in a secondary health facility, indications for their use and possibly consider how well they have been tolerated. We concluded that Dipyrone was commonly prescribed as analgesic and antipyretic at a secondary health facility in Ibadan, South-west Nigeria. There was no documentation of any untoward effects in the over 800 recipients of the drug during the one year period of the study.

\section{MATERIALS AND METHODS}

Location of Study

The study was conducted at Jericho General Hospital, Ibadan; a government owned secondary health care facility. The hospital caters for medical needs of patients, mainly adults. Only few children were seen as a hospital established for taking care of children is situated about $1.5 \mathrm{~km}$ from this hospital.

\section{Materials}

The case record file consists of card-boards usually stapled together for any particular patient. Patients' information including history, physical and laboratory findings and prescriptions are written on these cards. Once consultation was completed these case record files were sent to the Pharmacy Department of the Hospital where drugs were dispensed.

\section{Method}

We evaluated all prescriptions for patients who attended out-patients clinics of this general hospital for a period of 12 months, January to December 2003. The patients' records were assessed for age, sex, number and names of drugs prescribed and indications for such prescriptions. Special note was taken of prescriptions involving Dipyrone and other analgesic drugs. Incidences of multiple prescriptions involving Dipyrone and findings at subsequent follow-up of patients were also evaluated. All the information obtained was recorded in a format specially prepared for that purpose.

Data analysis was carried out using EPI-INFO version $6^{5}$. Proportions were compared using $X^{2}$ - tests while students t- test was used for continuous variables. Level of statistical significance was set at $\mathrm{p}<0.05$.

\section{RESULTS}

The total number of prescriptions assessed in the 12 months' period was 4,323. Of these 1,621 and 2,702 prescriptions were for male and female patients, respectively (table 1). The total number of drugs prescribed was 17,970 drugs. The mean number of drugs per prescription for males was $4.14 \pm 1.59$ (range $1-7$ ) and for females $4.17 \pm 1.58$ (range 1-7) drugs;

\begin{tabular}{|l|l|l|l|}
\hline & Female & Male & Statistics \\
\hline Number of prescription & 2702 & 1621 & \\
\hline Mean age & $31.84 \pm 14.38$ & $32.46 \pm 17.11$ & F: $0.15 ; \mathrm{P}>0.05$ \\
\hline Total number of drugs & 11252 & 6718 & \\
\hline $\begin{array}{l}\text { Mean drug } \\
\text { per prescription }\end{array}$ & $4.17 \pm 1.58$ & $4.14 \pm 1.59$ & F: $1.63 ; \mathrm{P}>0.05$ \\
\hline
\end{tabular}

Table 1: Gender distribution of prescriptions for analgesic drugs at Jericho General Hospital, Ibadan, Nigeria 
$p>0.05$. The total number of drugs prescribed for males and females being 6,718 and 11,252, respectively.

The mean age of female patients was $31.84 \pm 14.38$ (6-80) and males 32.46 \pm 17.11 (3-85) years. Children aged less than 15 years had only 364 or $8.4 \%$ of all the of which were administered by intramuscular injection, 2381 (55.7\%) were for Paracetamol, 61/4275 (1.4\%) were for Aspirin, $77 / 4275$ (1.7\%) were for Ibuprofen and the other analgesics including Tramadol, Diclofenac, Nimesulide and Piroxicam were prescribed in 944 or $22.1 \%$ cases. In all, 699, (50.4\%)

\begin{tabular}{|c|c|c|c|c|}
\hline DRUG GROUP & Male & Female & Total & Statistics \\
\hline NSAIDs & $\begin{array}{l}1641 \\
(24.4)\end{array}$ & $\begin{array}{l}2634 \\
(23.4)\end{array}$ & $\begin{array}{l}4275 \\
(23.7)\end{array}$ & $\begin{array}{l}X^{2} \cdot 2.48 \\
P>0.11\end{array}$ \\
\hline Antibacterial & $\begin{array}{l}1189 \\
(17.7)\end{array}$ & $\begin{array}{l}1618 \\
(14.4)\end{array}$ & $\begin{array}{l}2807 \\
(15.6)\end{array}$ & $\begin{array}{l}X^{2}: 35.45 \\
P<0.00\end{array}$ \\
\hline $\begin{array}{l}\text { Antimalarial drugs (e.g chloroquine, } \\
\text { artesunate, sulphadoxine plus } \\
\text { pyrimethamine, etc. }\end{array}$ & $\begin{array}{l}900 \\
(13.4)\end{array}$ & $\begin{array}{l}1564 \\
(13.9)\end{array}$ & $\begin{array}{l}2464 \\
(13.7)\end{array}$ & $\begin{array}{l}X^{2}: 0.05 \\
P>0.35\end{array}$ \\
\hline $\begin{array}{l}\text { Others including: psychoactive, } \\
\text { cardioactive, antiulcer antiviral anti- } \\
\text { asthma and Hyperglycemic drugs. }\end{array}$ & $\begin{array}{l}2988 \\
(44.5)\end{array}$ & $\begin{array}{l}5436 \\
(48.3)\end{array}$ & $\begin{array}{l}8424 \\
(46.9)\end{array}$ & $\begin{array}{l}X^{2}: 48.32 \\
P<0.00\end{array}$ \\
\hline Total & $\begin{array}{l}6718 \\
(37.4)\end{array}$ & $\begin{array}{l}11252 \\
(62.6)\end{array}$ & 17970 & \\
\hline
\end{tabular}

Table 2: Frequency distribution of various drugs prescribed compared between males and females (proportions are indicated in parenthesis)

prescriptions and 1676 or $9.3 \%$ of all drugs. There were similarities between the children population and adult in respect of distribution of various drugs such that in children and adults antimicrobial as well as analgesic drugs were commonly prescribed.

In all, the proportion of analgesics was found to be $23.8 \%$ (or 4275). The proportions for antibacterial, antimalarial and other drugs were $15.6 \%$ (or 2807), $13.7 \%$ (or 2467) and 46.9\% (or 8420), respectively. Prescriptions for antibacterial agents were proportionately more for males than females: 1189/ $6718(17.7 \%)$ versus $1618 / 11252(14.4 \%)$ respectively; $X^{2}: 35.45 P<0.00$ (table 2)

The proportions of analgesic/antipyretic drugs prescribed for male and female were respectively, $24.4 \%$ (or 1641) and 23.4\% (or 2634) (table 3). There was no statistically significant difference between the proportions of analgesic drugs prescribed for male and female patients. Of all the prescriptions for analgesics, 812/4275 (19.0\%) were Dipyrone 78.6\% of all the 1387 prescriptions for injections were for analgesic drugs. The remainder included prescriptions for antihistamines, antibacterial agents, mineral/vitamin supplements, antimalarial and antispasmodic agents. Of the prescriptions for intramuscular analgesic drugs, 638 (or 91.3\%) were Dipyrone. Diclofenac and Piroxicam injections were prescribed in $27(3.9 \%)$ and $2(0.3 \%)$ cases, respectively. There were only 32 prescriptions for opioid drugs namely, Tramadol (31) and Pentazocine (1).

The most commonly prescribed analgesic drug, Paracetamol, was prescribed with Dipyrone in 423 cases and in 30 cases, with other NSAIDs such as Pentazocine (1), Tramadol (3), Diclofenac (3), aspirin (1) and Nimesulide (22). Paracetamol was preferred as mono-analgesic drug in $1928(81.0 \%)$ while Dipyrone was similarly considered in 159 (19.6\%) of cases. Treatment of pain of traumatic origin accounted for only 50 of 2381 (2.1\%) prescriptions for Paracetamol whereas there were 98/812 (12.1\%) prescriptions for Dipyrone for similar condition. In 
all, there were 155 cases of trauma occasioned by fall, assault or road traffic accident. Thus Dipyrone was preferred in about $63 \%$ of such instances compared to about $32 \%$ preference for Paracetamol. do require analgesic agents. It is therefore understandable why majority of the prescriptions encountered were for antimicrobial and analgesic/ antipyretic agents.

\begin{tabular}{|l|l|l|l|}
\hline Drugs & Prescriptions for Analgesics & Oral & Intramuscular injection \\
\hline Paracetamol & $2381(55.7)$ & $2381(66.0)$ & - \\
\hline Dipyrone & $812(19.0)$ & $174(4.9)$ & $638(91.3)$ \\
\hline Aspirin & $61(1.4)$ & $61(1.7)$ & - \\
\hline Ibuprofen & $77(1.8)$ & $77(2.5)$ & - \\
\hline Others & $944(22.1)$ & $883(24.7)$ & $61(8.7)$ \\
\hline Total & $4275(100)$ & $3576(100.4)$ & $699(100)$ \\
\hline
\end{tabular}

Table 3: Pattern of prescriptions of Analgesic drugs and routes of administration (percentages are indicated in the parenthesis)

Paracetamol was justifiably preferred for the treatment of pain in patients with peptic ulcer disease and accounted for $86 / 108(79.6 \%)$ prescriptions for pain amongst such patients. However, Dipyrone was prescribed in $11(10.2 \%)$, Nimesulide in $9(8.3 \%)$ and Diclofenac in $2(1.8 \%)$ of such instances too. Ibuprofen, Aspirin and other NSAIDs were not prescribed for this population of patients. Except when diagnosis of Peptic Ulcer Disease was made, there was no evidence that efforts were made to include gastro-protective agents in the medication of patients who required NSAIDs. There was also no indication that COX-2 selective NSAIDs were prescribed during the period in review.

Adverse drug reactions were reported in only four cases with Chloroquine accounting for two cases, Pyrimethamine-Sulphadoxine was suspected in one case while overdose of Erythromycin was responsible for the other case. They were all mild reactions requiring only oral medication and outpatient management.

\section{DISCUSSION}

In this study, male and female patients were similarly represented and both received similar profile of drugs except antibacterial agents which were prescribed more often for males than females. In a tropical environment like ours, most hospitals attendees commonly present with infectious diseases. Other conditions like osteoarthritis, lacerations or cuts, blunt trauma and dislocation/fracture in addition to infectious diseases
The observation that significantly more men than women received antibacterial drugs during the period under review could not be easily explained. However, such finding may suggest that more men than women presented with infections and/or serious conditions.

The prescriptions as revealed in this study were rather skewed such that a lot more prescriptions were for adults. Only few of the children requiring medical attention presented at this hospital as the children hospital is situated nearby. The hospital was set up specifically to cater for the needs of civil servants, thus the preponderance of adult patients. There were similarities between the children population and adult in respect of distribution of various drugs such that in children and adults antimicrobial as well as analgesic/ antipyretic drugs were commonly prescribed. Most of the antimicrobial prescriptions were for treatment of either bacterial infections or malaria.

Paracetamol, given at the standard dose is safe and is employed in the treatment of mild to moderate pain of varied origin. The relative absence of major side effects common to other analgesic agents further enhances its acceptability. ${ }^{2}$ The drug lacks appreciable effects on both COX-1 and COX-2 and exact mechanism of action remains to be fully elucidated. The choice of Paracetamol in over 50\% of the prescriptions for analgesic drugs would be understandable from its tolerability and, in addition most patients presented with acute febrile or painful conditions. The second most commonly prescribed 
analgesic drug was Dipyrone with Ibuprofen placed third. It is interesting to note that Dipyrone was prescribed mainly in the injection form. In fact Dipyrone was the most commonly prescribed parenteral analgesic, accounting for $91.3 \%$ of all injections of analgesic drugs encountered in this study. Dipyrone, a Pyrazolone derivative has been banned in a number of European countries and the United States of America following its association with agranulocytosis. ${ }^{6,7}$ In Nigeria, Dipyrone was a very popular analgesic agent until the late 2005 when the drug regulatory agency in the country placed a ban on the use and sale of the drug under a controversial circumstance. Hitherto, indications for its use included post surgical, traumatic pain control and antipyretic effect.

It is of especial note that Dipyrone prescription was proportionately more than Paracetamol for the treatment of pain of traumatic origin. The dearth of effective alternative parenteral analgesic drugs might have been responsible. Agranulocytosis, toxic epidermal necrolysis and other serious untoward effects of Dipyrone were seemingly unknown in Nigeria where the only concern was the pain at injection site. Under-reporting might have been responsible for this observation though, indeed adverse drug events were reported in only four instances in this study. Lack of awareness on the part of the patients and negative attitudes of the physicians could be contributory. However, some recently conducted studies concluded that Dipyrone was safe and efficacious in management of pain of surgical and non surgical origins. ${ }^{8,9,10}$ Perhaps pharmacogenetics may provide an insight. Meanwhile, it will be essential to carry out a large epidemiological survey with a view to determining tolerance or otherwise of Dipyrone amongst Nigerian Africans.

It is noteworthy that none of the patients with Peptic Ulcer Disease who required analgesic drug was given Aspirin. However, some other NSAIDs were prescribed for some of them. Ideally, this class of drugs should have been avoided in this population of patients.

In conclusion, Dipyrone and other analgesic drugs were commonly prescribed in government owned secondary health care facility in Ibadan, Nigeria. Apparent lack of documentation of adverse effects may be due to attitudinal or genetic differences or yet to be identified reasons. Large prospective country wide study is urgently required to address this issue appropriately.

\section{REFERENCES}

1. Machewicz R, and Martin JB. In: Harrison's Principles of Internal Medicine $12^{\text {th }}$ Ed International Edition McGaw-Hill, 1991; 93-98

2. Inse1, PA In: Gilman and Goodman's The Pharmacological Basis of Therapeutics $9^{\text {th }}$ Ed International Edition McGaw-Hill, 1996; 617-643.

3. Juni P, Nartey L, Reichenbach S, Sterchi R, Dieppe PA, and Egger M. Risk of cardiovascular events and Rofecoxib: cumulative meta-analysis. The lancet 2004; 364:2021-2029

4. Graham DJ, Campen D, Hui R, Spence M, Cheetham C, Levy G, Shoor S, and Ray WA. Risk of acute myocardial infarction and sudden cardiac death in patients treated with cyclooxygenase 2 selective and non-steroidal anti-inflammatory drugs: nested case control study. The Lancet 2005; 365: 475-481

5. Dean AG, Dean JA, Coulomber D, Brendel KA, Smith DC, Burton AH, Dicker RC, Sullivan K, Fagan RF, and Arner TG. Epi Info Version 6: A word processing database and statistics program for public health on IBM-compatible microcomputer. Atlanta, Georgia: Centers for Control and Prevention and Geneva: World Health Organisation 1994.

6. Hedenmalm K, and Spigset O: Agranulocytosis and other blood dyscrasia associated with dipyrone (metamizole). Eur J Clin Pharmacol 2002; 58: 265274

7. Mary JY, Guiguet M, Baumelou E, and the French Cooperative Group for the Epidemiological Study of Aplastic Anaemia. Drug use and aplastic anaemia: the French experience. Eur J Haemathol 1996; 57(suppl):35-41.

8. Issaragrisil S, Kaufman DW, Anderson T, Chansung $\mathrm{K}$, et al. Low drug attributability of aplastic anemia in Thailand. Blood. 1997; 89: 4034-4039.

9. Bar-Oz B, Clementi M, Di Giantonio E, Greenberg R, Beer M, Merlob P, Arnon J, Ornoy A, Zimmerman DM, and Berkovitch M. Metamizol (dipyrone, optalgin) in pregnancy, is it safe? A prospective comparative study. Eur J Obstet Gynecol Reprod Biol. 2005; 119(2):176-179.

10. Martinez-Martin P, Rafaelli E Jr, Titus F, et al. Efficacy and safety of metamizol vs. acetylsalicylic acid in patients with moderate episodic tension-type headache: a randomized, double-blind, placebo- and active-controlled, multicentre study. Cephalalgia 2001; 21(5): 604-610. 